\title{
Ultraviolet Detectors Based on ZnO:N Thin Films with Different Contact Structures
}

\author{
A. Ievtushenko ${ }^{a}$, G. Lashkarev ${ }^{a}$, V. Lazorenko $^{a}$, \\ V. KARPYNA ${ }^{a}$, V. SichKOVSKYi ${ }^{a}$, L. KOSYACHENKO $^{b}$, \\ V. SklyarchuK ${ }^{b}$, O. SklyarchuK ${ }^{b}$, V. Bosy ${ }^{c}$, F. Korzhinski ${ }^{c}$, \\ A. Ulyashin ${ }^{d}$, V. KhrANOVSKYY ${ }^{e}$ AND R. YAKImOVA ${ }^{e}$ \\ ${ }^{a}$ Institute for Problems of Material Science, NASU \\ Krzhyzhanovskyy str. 3, 03142, Kiev, Ukraine \\ ${ }^{b}$ Chernivtsi National University \\ Kotsyubinsky str. 2, 58012, Chernivtsi, Ukraine \\ cJSCP SPU "Saturn", 50-let Oktybrya av. 2b, 03148, Kiev, Ukraine \\ ${ }^{d}$ SINTEF Materials and Chemistry \\ Forskningsveien 1, Blindern, NO-0314 Oslo, Norway \\ ${ }^{e}$ Linkoping University, Department of Physics, Chemistry and Biology (IFM) \\ 58183 Linköping, Sweden
}

\begin{abstract}
$\mathrm{Al} / \mathrm{ZnO}: \mathrm{N} / \mathrm{Al}$ and $\mathrm{Ni} / \mathrm{ZnO}: \mathrm{N} / \mathrm{Al}$ diode photodetectors fabricated by dc magnetron sputtering of $\mathrm{ZnO}: \mathrm{N}$ films on $p$-Si substrates are studied. The photocurrent-to-dark current ratio equal to 250 at $\lambda=390 \mathrm{~nm}$ and the time constant of photoresponse about $10 \mu \mathrm{s}$ for $\mathrm{Al} / \mathrm{ZnO}: \mathrm{N} / \mathrm{Al}$ structures with $4 \mu \mathrm{m}$ interdigital spacing was achieved. The $\mathrm{Ni} / \mathrm{ZnO}: \mathrm{N} / \mathrm{Al}$ diode structure has the rectification ratio $\approx 10^{2}$ at bias $1 \mathrm{~V}$, the maximal responsivity about $0.1 \mathrm{~A} / \mathrm{W}$ is observed at $365 \mathrm{~nm}$, and the measured time constant of photoresponse is about $100 \mathrm{~ns}$.
\end{abstract}

PACS numbers: 81.05.Dz, 81.15.Cd, 85.60.Dw, 72.40.+w

\section{Introduction}

Ultraviolet (UV) detectors have attracted great interest during recent years, due to their applications such as missile warning systems, solar astronomy, high temperature flame detection, precise measurement of UV radiation effect on human body, ozone layer monitoring, etc. [1-3]. 
$\mathrm{ZnO}$ is a direct wide band gap $\left(E_{\mathrm{g}}=3.4 \mathrm{eV}\right)$ semiconductor material which can be used for UV photon detection. $\mathrm{ZnO}$ has optical and electrical properties similar to GaN. Nevertheless, it possesses such preferences as relative cheapness, non-toxicity, advantages in technology and resistance to radiation damage.

Recently, many publications have appeared in literature devoted to creation of $\mathrm{ZnO}$ based photoresistors and Schottky photodiodes for UV spectrum region. For the photoresistors it is easy to obtain higher photoresponsivity. Also the amplifying equipment is not necessary and the measuring system is simple and cheap. However, its photoresponsivity has a nonlinear behavior with incident power, poor UV/visible contrast, and persistent photoconductivity response. Furthermore, the photoresponse time of photoconductive detector is usually longer than other types of detectors [4].

In Ref. [5] photoconductive detectors based on $\mathrm{ZnO}$ thin films were obtained. These detectors were sensitive to UV radiation, but had a large photoresponse time due to $\mathrm{O}_{2}$ adsorption-desorption processes from surface. Authors of Ref. [6] demonstrated that doping by nitrogen improves properties of $\mathrm{ZnO}$ detectors such as time constant up to microseconds. According to the early report, doping by nitrogen increases photoresponsivity of $\mathrm{ZnO}$ based detectors and decreases time constant due to acceleration of adsorption-desorption processes of molecules $\mathrm{O}_{2}$ and $\mathrm{C}$ from surface of $\mathrm{ZnO}: \mathrm{N}$ thin film [7].

The purpose of this work is creation of photoresistor and diode structure on the basis of $\mathrm{ZnO}$, doped by nitrogen $(\mathrm{ZnO}: \mathrm{N})$, and research of their electric and photoelectric characteristics. We report on the epitaxial growth of $c$-preferred oriented $\mathrm{ZnO}$ films, doped by nitrogen as acceptor impurity (ZnO:N), on $p$-Si $\left(\begin{array}{lll}1 & 0 & 0\end{array}\right)$ substrate by dc magnetron sputtering in nitrogen plasma, as well as the fabrication and characterization of photoconductive $\mathrm{Al}-\mathrm{ZnO}-\mathrm{Al}$ metal-semiconductor-metal (MSM) structure and $\mathrm{Ni} / \mathrm{ZnO}: \mathrm{N} / \mathrm{Al}$ diode as $\mathrm{UV}$ radiation detectors.

\section{Experimental procedure}

\subsection{Sample preparation}

$\mathrm{ZnO}: \mathrm{N}$ thin films were deposited on $p$-Si $\left(\begin{array}{lll}1 & 0 & 0\end{array}\right)$ substrate by dc magnetron sputtering in nitrogen plasma. All $\mathrm{ZnO}$ films (undoped and $\mathrm{N}$ doped) were deposited by magnetron sputtering using $\mathrm{ZnO}$ sintered target slightly doped by $\mathrm{Al}$. Dc magnetron sputtering was carried out in vacuum chamber with total gas pressure 4 mTorr at magnetron power $1200 \mathrm{~W}$. ZnO samples without nitrogen were deposited in $\mathrm{Ar}$ gas ambient. $\mathrm{N}$-doped $\mathrm{ZnO}$ films were deposited by sputtering $\mathrm{ZnO}$ target in $\mathrm{N}_{2} / \mathrm{Ar}(10 / 1)$ gases ambient. Target-substrate distance was $3 \mathrm{~cm}$. For all depositions growth temperature $T_{\mathrm{s}}$ was $25^{\circ} \mathrm{C}$. The thickness of the layers was about $100 \mathrm{~nm}$.

$\mathrm{Al} / \mathrm{ZnO}: \mathrm{N} / \mathrm{Al}$ interdigital transducer (IDT) MSM structures were formed using standard lift-off lithography. Before formation of IDT structure by $\mathrm{Al}(300 \mathrm{~nm})$ deposition, the surface was cleaned in $\mathrm{O}_{2}$ plasma during 5 min. Al electrodes were 


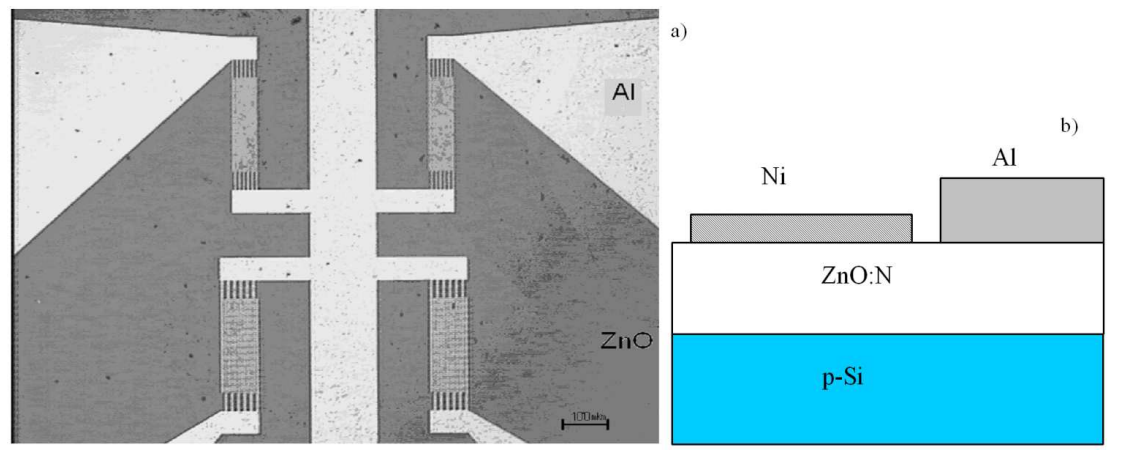

Fig. 1. (a) SEM picture of $\mathrm{ZnO}: \mathrm{N}$ UV detector with MSM structure. The Al fingers are $580 \mu \mathrm{m}$ long, 4 and $6 \mu \mathrm{m}$ wide and have an interelectrode spacing of 4 and $6 \mu \mathrm{m}$, respectively; (b) schematic image of surface-barrier $\mathrm{Ni} / \mathrm{ZnO}: \mathrm{N} / \mathrm{Al}$ diodes.

sputtered by electron beam evaporation (Fig. 1a). In $\mathrm{Ni} / \mathrm{ZnO}: \mathrm{N} / \mathrm{Al}$ diode structure the rectifying ultrathin $\mathrm{Ni}(20 \mathrm{~nm})$ contact to $\mathrm{ZnO}: \mathrm{N}$ film was formed by vacuum thermal evaporation (VTE). Before formation of Ni contact, the surface of $\mathrm{ZnO}: \mathrm{N}$ film was cleaned in Ar plasma during 5 min. After that we deposited $\mathrm{Al}$ (200 nm) electrode using VTE (Fig. 1b). For investigation of semiconductor-metal interface quality and nitrogen impurity effect, we also deposited non-doped $\mathrm{ZnO}$ thin films on $p$-Si $\left(\begin{array}{lll}1 & 0 & 0\end{array}\right)$ substrate and fabricated the same contact structures to them.

\subsection{Sample characterization}

The structural properties were measured by X-ray diffraction (XRD) using a Siemens D5000 diffractometer, utilizing $\mathrm{Cu} K_{\alpha}$ radiation $(\lambda=0.1542 \mathrm{~nm})$. The photoluminescence (PL) properties were studied by femtosecond Ti:sapphire laser (37 mW, $170 \mathrm{fs}, 76 \mathrm{MHz})$. The surface morphology was examined by atomic force microscopy (AFM - Veeco Digital Instruments Nanoscope 3100) in tapping mode. The electrical measurements were carried out using Keithley 2700/Module 7700. Spectral photoresponse measurements were performed using KGM-70 lamp in combination with monochromator MDR-4. The precision silicon photodetector (FD286) was used to control the optical power on the detector. The photoresponse speed of the detector was also measured. The signal from a $100 \Omega$ load resistor was recorded by oscilloscope with a time resolution better than 1 ns, using $9 \mathrm{~V}$ bias voltage.

\section{Results and discussion}

Figure 2 shows the XRD pattern of $\mathrm{ZnO}$ thin film prepared by dc magnetron sputtering. Only the (002) diffraction peak of $\mathrm{ZnO}$ at $33.98^{\circ}$ with the full width at half maximum (FWHM) of $0.4^{\circ}$ could be found. Therefore, it is obvious that the film has preferred orientation along $c$-axis. The diffraction peak at $32.95^{\circ}$ belongs 
to $\mathrm{Si}$ substrate. The magnitude of this peak indicates that thickness of $\mathrm{ZnO}: \mathrm{N}$ film is small. Figure 3 shows AFM images of the $\mathrm{ZnO}: \mathrm{N}$ films. $\mathrm{ZnO}$ films doped by nitrogen are of polycrystalline nature with characteristic grain size diameter $58 \pm 15 \mathrm{~nm}$ and surface root mean square roughness $5.2 \mathrm{~nm}$. The XRD spectra of $\mathrm{ZnO}$ films demonstrates only the reflection peaks peculiar to $\mathrm{ZnO}$ wurzite structure which is in coincidence with atomic force microscopy analysis.



Fig. 2. XRD $\theta-2 \theta$ spectra of a $\mathrm{ZnO}: \mathrm{N} / p$-Si film.

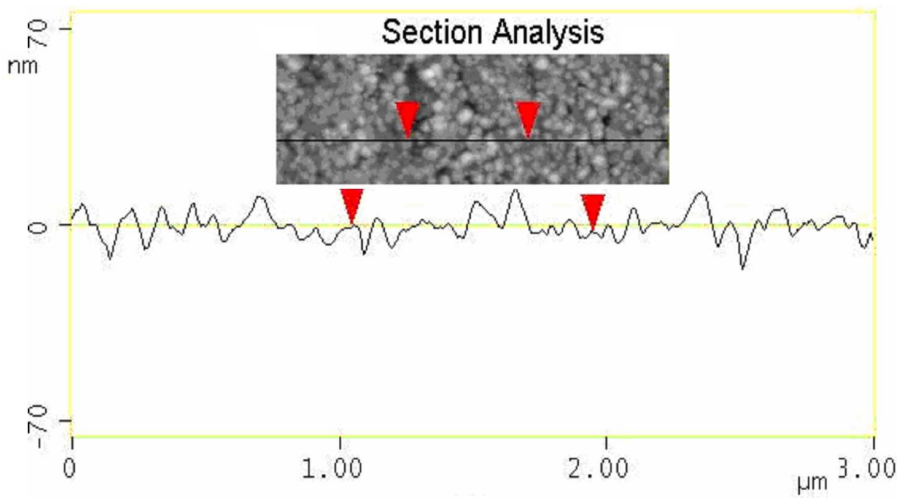

Fig. 3. AFM images of a $\mathrm{ZnO}: \mathrm{N} / p$-Si film.

We also studied photoluminescence of as-grown $\mathrm{ZnO}$ and $\mathrm{ZnO}$ doped $\mathrm{N}$ films by femtosecond Ti:sapphire laser at room temperatures. No photoluminescence was observed for all $\mathrm{ZnO} / p$-Si films. It is related to low crystalline and optic quality of $\mathrm{ZnO}$ and $\mathrm{ZnO}: \mathrm{N}$ thin films due to their low thickness.

Shown in Fig. 4 are the $I-V$ characteristics of the fabricated $\mathrm{Al} / \mathrm{ZnO}: \mathrm{N} / \mathrm{Al}$ IDT structure (a) and $\mathrm{Ni} / \mathrm{ZnO}: \mathrm{N} / \mathrm{Al}$ diodes (b). The linear dependence of $I-V$ curve from the $\mathrm{Al} / \mathrm{ZnO}: \mathrm{N} / \mathrm{Al}$ structure clearly indicates the ohmic behavior of the 
$\mathrm{Al}$ contact to $\mathrm{ZnO}: \mathrm{N}$ film. On the other hand, the rectified $I-V$ curve of the $\mathrm{Ni}-$ $\mathrm{ZnO}$ contact confirms junction formation between $\mathrm{Ni}$ and $n$-type $\mathrm{ZnO}$ doped by $\mathrm{N}$. In this paper we will consider only $4 \mu \mathrm{m} \mathrm{Al} / \mathrm{ZnO}: \mathrm{N} / \mathrm{Al}$ IDT structures because $I-V$ characteristics, spectral photoresponses and time constants of $4 \mu \mathrm{m}$ and $6 \mu \mathrm{m}$ $\mathrm{Al} / \mathrm{ZnO}: \mathrm{N} / \mathrm{Al}$ IDT structures have similar behavior.
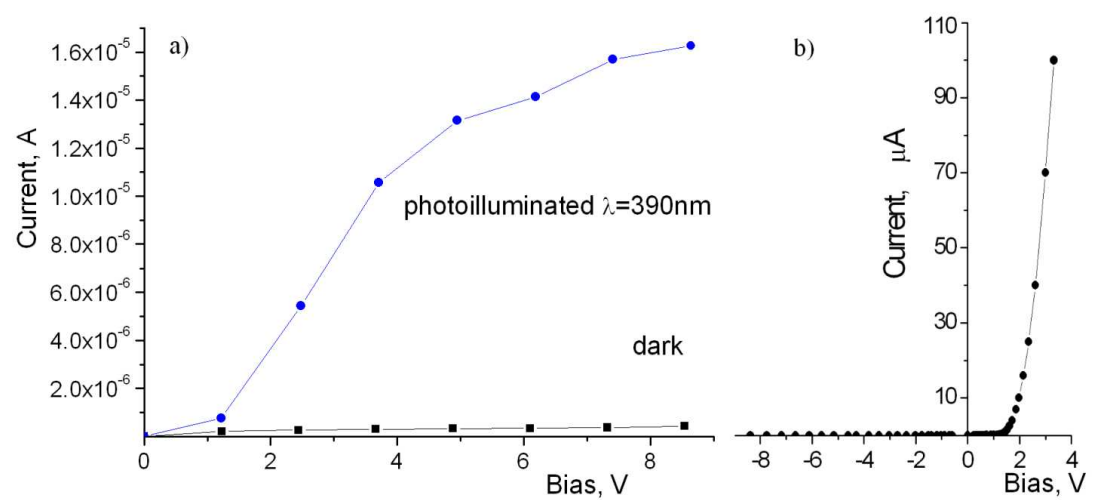

Fig. 4. $I-V$ characteristics of the fabricated $\mathrm{Al} / \mathrm{ZnO}: \mathrm{N} / \mathrm{Al}$ IDT structure (a) and $\mathrm{Ni} / \mathrm{ZnO}: \mathrm{N} / \mathrm{Al}$ diode (b).

We achieved a photocurrent-to-dark current ratio about 250 for $4 \mu \mathrm{m}$ and $6 \mu \mathrm{m} \mathrm{Al} / \mathrm{ZnO}: \mathrm{N} / \mathrm{Al}$ IDT structures peaked at around $390 \mathrm{~nm}$. Under $3 \mathrm{~V}$ bias, the measured average dark current for $\mathrm{Al} / \mathrm{ZnO}: \mathrm{N} / \mathrm{Al}$ structure is $350 \mathrm{nA}$ (Fig. 4a). This is much smaller compared with Ref. [8]. The low dark current is desirable to enhance the detector's signal-to-noise $(\mathrm{S} / \mathrm{N})$ ratio since the shot noise, which exceeds the Johnson and $1 / f$ noise if the operating frequency is not too low, is proportional to dark current [9]. Furthermore, it should be noted that the light current did not linearly increase above $5 \mathrm{~V}$ applied bias, indicating the sweep-out effect up to this bias [10].

$\mathrm{Ni} / \mathrm{ZnO}: \mathrm{N} / \mathrm{Al}$ diode structure has high rectification ratio about $10^{2}$ at bias $1 \mathrm{~V}$ (Fig. 4b). The $I-V$ characteristics for a Schottky diode is expressed by [11]:

$$
J=J_{0}\left[\exp \left(\frac{e V}{n k T}\right)-1\right],
$$

where $J_{0}=A T^{2} \exp \left(\Phi_{\mathrm{B}} / k T\right)$ is the saturation current density according to thermionic emission theory, $n$ - ideality factor, $k$ - the Boltzmann constant, $T$ - the absolute temperature, $A$ - effective Richardson coefficient, and $\Phi_{\mathrm{B}}$ - the barrier height. The ideality factor was calculated by $I-V$ curve fitting (Fig. 4b) and value of $n=7$ was obtained.

The spectral photoresponse of $\mathrm{Al} / \mathrm{ZnO}: \mathrm{N} / \mathrm{Al}$ IDT structure (biased at $2 \mathrm{~V}$ ) is shown in Fig. 5a. The maximum of photoresponsivity peaked at around $380 \mathrm{~nm}$. In this case the fabricated detectors are sensitive to visible irradiation because of 

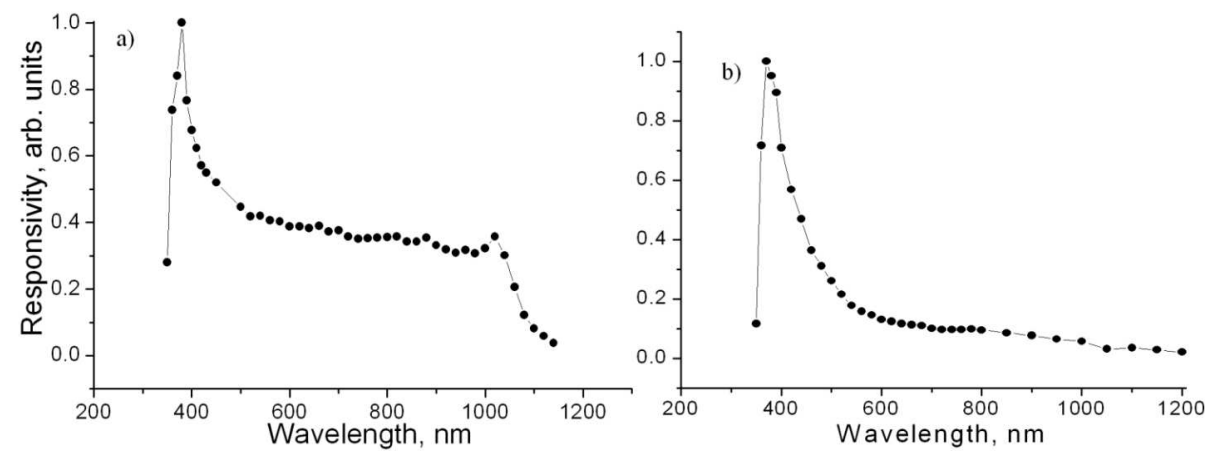

Fig. 5. Spectral photoresponse of the $\mathrm{ZnO}: \mathrm{N}$ photodetectors: (a) Al/ZnO:N/Al IDT structure (biased at $2 \mathrm{~V}$ ) and (b) $\mathrm{Ni} / \mathrm{ZnO}: \mathrm{N} / \mathrm{Al}$ diode (biased at $-1 \mathrm{~V}$ ).
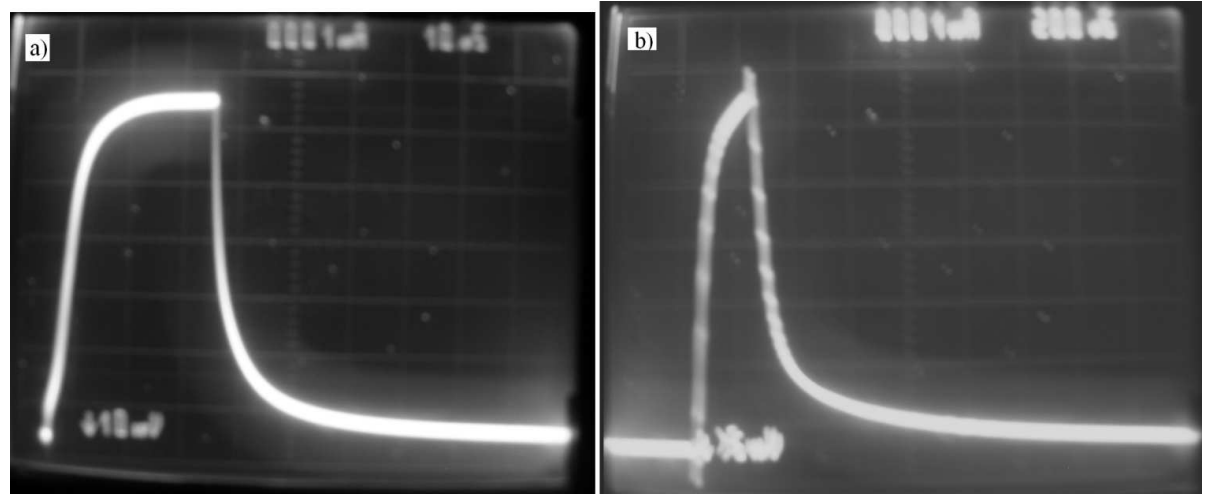

Fig. 6. Temporal response of $\mathrm{ZnO}: \mathrm{N}$ photodetectors: (a) Al/ZnO:N/Al IDT structure ( $x$ scale interval is $10 \mu \mathrm{s}$ ) and (b) $\mathrm{Ni} / \mathrm{ZnO}: \mathrm{N} / \mathrm{Al}$ diode ( $x$ scale interval is $200 \mathrm{~ns}$ ).

short circuit formatted by $p$-Si substrate, which is sensitive in this spectral region, while $\mathrm{ZnO}: \mathrm{N}$ film is a window for visible radiation.

The spectral photoresponse of $\mathrm{Ni} / \mathrm{ZnO}: \mathrm{N} / \mathrm{Al}$ diodes is shown in Fig. 5b. The maximum of photoresponsivity about $0.1 \mathrm{~A} / \mathrm{W}$ peaked at around $365 \mathrm{~nm}$. The cut-off at wavelength of $365 \mathrm{~nm}$ agrees with the $\mathrm{ZnO}$ energy band gap of $3.4 \mathrm{eV}$. The responsivity decreases at the shorter wavelength range due to decrease in the penetrating depth of the light, resulting in an increase in the surface recombination. The spectrum of responsivity ranged up to $1200 \mathrm{~nm}$ due to presence of structural defects in $\mathrm{ZnO}: \mathrm{N}$ films and photosensitivity of $\mathrm{Si}$ substrate to visible radiation.

Figure 6 shows the temporal response of the $\mathrm{ZnO}$ :N photodetectors with $9 \mathrm{~V}$ bias and $100 \Omega$ load resistor. Calculated by exponential function fitting, the time constant of $\mathrm{Al} / \mathrm{ZnO}: \mathrm{N} / \mathrm{Al}$ IDT MSM structures was found to be $10 \mu \mathrm{s}$. Also the time constant of $\mathrm{Ni} / \mathrm{ZnO}: \mathrm{N} / \mathrm{Al}$ diode was about 100 ns. A large magnitude of time constant for $\mathrm{Al} / \mathrm{ZnO}: \mathrm{N} / \mathrm{Al}$ IDT MSM structures can be explained by the oxygen adsorption at the surface and by presence of grain boundaries in polycrystalline 
ZnO:N film leading to appearance of trap states. All detectors based on $\mathrm{ZnO}: \mathrm{N}$ films demonstrated high stability in time.

Photosensitivity of $\mathrm{Al} / \mathrm{ZnO} / \mathrm{Al} \mathrm{MSM}$ photodetectors was very low (photocurrent-to-dark current ratio was only 0.05). Also temporal response of the detectors based on undoped $\mathrm{ZnO}$ films show a significant larger value of time constant (tens of minutes) than $\mathrm{Al} / \mathrm{ZnO}: \mathrm{N} / \mathrm{Al}$ MSM photodetectors. Moreover, resistivity of $\mathrm{ZnO}$ films was of order twice lower than nitrogen doped $\mathrm{ZnO}$ films. This result testifies that nitrogen incorporates in $\mathrm{ZnO}$ film.

We believe that excellent photoelectric characteristics of obtained $\mathrm{ZnO}: \mathrm{N}$ films is due to positive nitrogen role in suppression of crystal lattice defects in $\mathrm{ZnO}$ formed by oxygen vacancies. More advanced experiments are needed to determine nitrogen role in $\mathrm{ZnO}$.

\section{Summary}

$\mathrm{Al} / \mathrm{ZnO}: \mathrm{N} / \mathrm{Al}$ MSM IDT structures and $\mathrm{Ni} / \mathrm{ZnO}: \mathrm{N} / \mathrm{Al}$ diode structures were obtained by magnetron sputtering. Photocurrent-to-dark current ratio $250(\lambda=$ $390 \mathrm{~nm}$ ) for $\mathrm{Al} / \mathrm{ZnO}: \mathrm{N} / \mathrm{Al}$ IDT MSM structures with $4 \mu \mathrm{m}$ interdigital spacing was achieved. Time constant of photoresponse was about $10 \mu \mathrm{s}$. Ni/ZnO:N/Al diode structure has high rectification ratio $\left(\approx 10^{2}\right.$ at bias $\left.1 \mathrm{~V}\right)$. The maximal responsivity about $0.1 \mathrm{~A} / \mathrm{W}$ was achieved at $365 \mathrm{~nm}$. The measured time constant of photoresponse was about $100 \mathrm{~ns}$.

\section{References}

[1] S.J. Young, L.W. Ji, S.J. Chang, Y.K. Su, J. Cryst. Growth. 293, 43 (2006).

[2] H. Ohta, M. Kamiya, T. Kamiya, M. Hirano, H. Hosono, J. Thin Solid Films 445, 317 (2003).

[3] D. Basak, G. Amin, B. Mallik, G.K. Paul, S.K. Sen, J. Cryst. Growth 256, 73 (2003).

[4] K.W. Liu, J.G. Ma, J.Y. Zhang, Y.M. Lu, D.Y. Jiang, B.H. Li, D.X. Zhao, Z.Z. Zhang, B. Yao, D.Z. Shen, J. Solid-State Electron. 51, 757 (2007).

[5] D.H. Zang, D.E. Brodie, J. Thin Solid Films 251, 151 (1994).

[6] Y. Liu, C.R. Gorla, S. Liang, N. Emanetoglu, Y. Lu, H. Shen, M. Wraback, J. Electronic Mater. 29, 69 (2000).

[7] Y.J. Zeng, Z.Z. Ye, Y.F. Lu, J.G. Lu, W.Z. Xu, L.P. Zhu, B.H. Zhao, In. Che, J. Chem. Phys. Lett. 441, 115 (2007).

[8] Q.A. Xu, J.W. Zhang, K.R. Ju, X.D. Yang, X. Hou, J. Cryst. Growth 289, 44 (2006).

[9] W. Yang, R.D. Vispute, S. Choopun, R.P. Sharma, T. Venkatesan, H. Shen, J. Appl. Phys. Lett. 78, 2787 (2001).

[10] M. Razeghi, A. Rogalski, J. Appl. Phys. 79, 7433 (1996).

[11] S. Liang, H. Sheng, Y. Liu, Z. Huo, Y. Lu, H. Shen, J. Crystal Growth 225, 110 (2001). 